\title{
Cold Pressor Test, Moderate Anaemia in Second and Third Trimester of Pregnancy
}

\author{
Jigna B. Kher' ${ }^{1}$ Anju Jain ${ }^{2}$, Kuldeep Atodaria ${ }^{3}$, Chinmay Shah ${ }^{4}$, \\ Rajkumar Bansal $^{5}$, Hetal Desai ${ }^{6}$, Jignesh Vaishnani ${ }^{7}$ \\ ${ }^{1}$ Tutor, MD Physiology, ${ }^{2}$ Assistant Professor, Smimer, Surat, Gujrat, ${ }^{3}$ MBBS, GMC, Surat, Main Statistical Data \\ Analyser, Gujrat, ${ }^{5}$ MD Physiology, Associate Professor, GMC, Bhavnagar, Gujrat, India ${ }^{5}$ Professor and Dean, \\ ${ }^{6}$ MD Physiology, Professor and Head, Physiology, ${ }^{7}$ MD Skin, Ethical Committee Guide and Mentor, Smimer, \\ Surat, Gujrat, India
}

\begin{abstract}
Background: $2^{\text {nd }} \& 3^{\text {rd }}$ trimester of pregnancy is associated with profound adaptive autonomic cardiovascular changes. Anaemia in pregnancy, which is a common problem in India is known to put pregnant female at higher cardiovascular risk.

Objective: The aim of this study is to measure \& compare DBP response to CPT in both trimester in both control group \& pregnancy with moderate anaemia (Case) for screening \& diagnosis of autonomic imbalance.

Method: After measuring vitaldata, anthropometric data, DBP response to CPT were measured \& compared among control \& case group (13-39 weeks of gestation) in sitting position.

Result: A highly significant difference in Wt, SBP, DBP were observed in control group of $2^{\text {nd }}$ trimester when compared with $3^{\text {rd }}$ trimester. A highly significant difference was observed in Wt, DBP, DBP response to CPT of case group of $2^{\text {nd }}$ trimester when compared with $3^{\text {rd }}$ trimester; A highly significant difference was observed in $\mathrm{Hb}$, SBP, DBP of case group of $3^{\text {rd }}$ trimester when compared with control group during $3^{\text {rd }}$ trimester of pregnancy; The chi-square test value shows that the observed DBP response to CPT in moderately anaemic pregnancy during $2^{\text {nd }} \& 3^{\text {rd }}$ trimester is not due to chance.

Conclusion: This study has found CPT as simple, safe, cost effective, reliable test aiding to understand pathophysiology of anaemia during late gestation. It is also useful tool to predict \& screen high risk pregnancy among anaemic pregnancies for early intervention.
\end{abstract}

Keywords: Cold Pressor Test (CPT), Anaemia, Autonomic imbalance, Diastolic Blood Pressure (DBP).

\section{Introduction}

A pre-eclampsia prevalence is of $7.5 \%$ of all pregnancies \& it was found tobe slightly higher in primigravida ${ }^{1}$ pregnancy with anemia ${ }^{2,3}$, forms the base of doing our study in primigravida. Rang et al argued that since a higher sympathetic nervous activity has been observed in pre-eclampsia, changes in autonomic control preceding the onset of pre-eclampsia could provide early identification \& it is essential for prophylactic interventions to reduce morbidity \& mortality associated with this syndrome explains the aim of performing this study. ${ }^{4,5}$ Different studies have been performed about the etiology of pre-eclampsia but there is no reliable $\&$ cost-effective screening test. ${ }^{6,7}$ Although inflammation $\&$ extensive endothelial dysfunction of vessels are the main possible mechanisms of pre-eclampsia, but the pathogenesis of this syndrome has not been well understood. ${ }^{6}$ Conducting this study in pregnant women with anaemia will aid to understand pathogenesis of this syndrome. The cold water causes stimulation of cold \& pain receptors in the hand. The information is carried 
to the brain through spinothalamic pathways. The reflex involves, rise in sympathetic outflow to the vasculature $\&$ heart resulting in rise in $\mathrm{BP} .{ }^{8}$ Results revealed that women when assessed at 12-20 weeks of gestation, who developed PIH subsequently, had heightened response to CPTin the form of more increase in both systolic \& diastolic BP as compared to healthy pregnant women, who did not develop PIH. ${ }^{9}$ Woisetschlerger ${ }^{10}$ also had same observation \& attributed this increase to increased vasoconstrictive response to physiological stimulus (cold).Studies show that significantly high incidences of development of PIH in late trimester in the healthy pregnant women who had shown higher cut off Values of BP response during CPT performed during early trimester of pregnancy, forms valuable objective for conducting our study to identify $\mathrm{CPT}$ as a routine screening test in pregnancy with moderate anaemia. ${ }^{11}$

Materials and Method: After obtaining approval from Institutional Ethical Comittee, CPT was performed in Applied Physiology laboratory from 9.00 a.m. to 11 a.m. at $24^{\circ} \mathrm{C}-26^{\circ} \mathrm{C}$ room temperature, of pregnant females (13-39 wksof gestation period) attending Antenatal Clinic of SMIMER Hospital, age 18-45 $\mathrm{yr}$, with singleton pregnancy, who were ready to give written informed consent. In the control group, pregnant females with $\mathrm{Hb}$ level $\geq 11.0 \mathrm{~g} / \mathrm{dl} \&$ In a case group, pregnant females with moderate anaemia having $\mathrm{Hb}$ level between $7.0 \mathrm{~g} / \mathrm{dl}$ to $9.9 \mathrm{~g} / \mathrm{dl}$, were assessed. For both group exclusion criteria were:

- H/o Multiple Pregnancy (e.g. Twins, triplets,etc.)

- H/o Significant illness of any system especially cardiovascular \& Ventilatory System \& other illness (e.g. malaria, asthma, tuberculosis)

- H/o Habit of smoking,drugs/alcohol intake or use of therapeutic drugs Esp. sympathomimetic drugs/ blockers.

- Females with pregnancy induced complication (e.g. Hypertension, Diabetes, Pre-eclampsia, Toxaemia of pregnancy).

Subjects were explained the procedure \& were asked to avoid tea, coffee, food 2 hrs. prior to study. Anthropometric Data (height, weight) were measured on Standard Measuring Scale. Vital Data temperature, pulse rate, BP were assessed in supine position. CPT (cold pressor test): The test is performed in sitting position. ${ }^{8}$ Digital BP instrument was calibrated with standard sphygmomanometer. First the baseline BP was measured using digital BP instrument $\&$ then the subject was instructed about the test. Cold water of $10^{\circ} \mathrm{C}$ was prepared \& maintained at that temperature. The subject was asked to immerse the hand in water up to the wrist for $1 \mathrm{~min}$. without touching the bottom of the cold water bath. After that the hand was removed from the water \& it was covered with towel. The DBP was measured in contra lateral arm just before the hand was taken out of water. The DBP was taken again at $1.5 \mathrm{~min} \& 4 \mathrm{~min}$ after the hand was withdrawn from the cold water. Highest DBP value was considered for calculation. Data were analysed using licensed SPSS 16.0 software. Statistical tests In dependant t-test, ANOVA (Mann-Whitney test), Chi-square test were used to analyse the obtained data. Results were considered significant at $\mathrm{p}$ value $<0.05$ $\&$ highly significant at $\mathrm{p}$ value $<0.01$.

\section{Observation:}

Table No. 1: Comparison of Mean of Parameters Between $2^{\text {nd }} \& 3^{\text {rd }}$ Trimester (Control Group)

\begin{tabular}{|c|c|c|c|c|c|}
\hline Parameter & Trimester & $\mathbf{N}$ & Mean & SD & p-value \\
\hline \multirow{2}{*}{ Age (Years) } & $2^{\text {nd }}$ & 30 & 22.40 & 3.74 & \multirow{2}{*}{0.932} \\
\hline & $3^{\text {rd }}$ & 46 & 22.32 & 3.30 & \\
\hline \multirow{2}{*}{$\mathrm{Hb}(\mathrm{gm} \%)$} & $2^{\text {nd }}$ & 30 & 11.36 & 0.50 & \multirow{2}{*}{0.085} \\
\hline & $3^{\text {rd }}$ & 46 & 11.63 & 0.73 & \\
\hline \multirow{2}{*}{$\mathrm{Ht}(\mathrm{cm})$} & $2^{\text {nd }}$ & 30 & 150.90 & 5.23 & \multirow{2}{*}{0.417} \\
\hline & $3^{\text {rd }}$ & 46 & 152.02 & 6.22 & \\
\hline \multirow{2}{*}{ Wt (kg) } & $2^{\text {nd }}$ & 30 & 48.56 & 12.82 & \multirow{2}{*}{$0.0001^{* *}$} \\
\hline & $3^{\text {rd }}$ & 46 & 81.85 & 7.48 & \\
\hline
\end{tabular}




\begin{tabular}{|c|c|c|c|c|c|}
\hline Parameter & Trimester & $\mathbf{N}$ & Mean & SD & p-value \\
\hline \multirow{2}{*}{ Pulse Rate (bpm) } & $2^{\text {nd }}$ & 30 & 90.40 & 10.80 & \multirow{2}{*}{0.464} \\
\hline & $3^{\text {rd }}$ & 46 & 92.65 & 14.27 & \\
\hline \multirow{2}{*}{$\mathrm{SBP}(\mathrm{mmHg})$} & $2^{\text {nd }}$ & 30 & 104.33 & 9.26 & \multirow{2}{*}{$0.006^{* *}$} \\
\hline & $3^{\text {rd }}$ & 46 & 96.10 & 14.15 & \\
\hline \multirow{2}{*}{ DBP (mmHg) } & $2^{\text {nd }}$ & 30 & 64.86 & 7.15 & \multirow{2}{*}{$0.0001^{*}$} \\
\hline & $3^{\text {rd }}$ & 46 & 109.58 & 12.85 & \\
\hline \multirow{2}{*}{ CPT (mmHg) } & $2^{\text {nd }}$ & 30 & 8.30 & 11.89 & \multirow{2}{*}{0.157} \\
\hline & $3^{\text {rd }}$ & 46 & 5.27 & 6.46 & \\
\hline
\end{tabular}

A highly significant difference in Wt, SBP, DBP were observed in Control Group of $2^{\text {nd }}$ trimester when compared with $3^{\text {rd }}$ trimester. No significant difference was observed in Age, Ht, Hb, Pulse rate, DBP response to CPT (Table No. 1).

Table No. 2: Comparison of Mean of Parameters between $2^{\text {nd }} \& 3^{\text {rd }}$ Trimester (Case Group)

\begin{tabular}{|c|c|c|c|c|c|}
\hline Parameter & Trimester & $\mathbf{N}$ & Mean & SD & p-value \\
\hline \multirow{2}{*}{ Age (Years) } & $2^{\text {nd }}$ & 50 & 21.94 & 2.90 & \multirow{2}{*}{0.835} \\
\hline & $3^{\text {rd }}$ & 52 & 21.82 & 2.88 & \\
\hline \multirow{2}{*}{$\mathrm{Hb}(\mathrm{gm} \%)$} & $2^{\text {nd }}$ & 50 & 9.06 & 0.79 & \multirow{2}{*}{0.949} \\
\hline & $3^{\text {rd }}$ & 52 & 9.07 & 0.80 & \\
\hline \multirow{2}{*}{$\mathrm{Ht}(\mathrm{cm})$} & $2^{\text {nd }}$ & 50 & 150.18 & 5.06 & \multirow{2}{*}{0.102} \\
\hline & $3^{\text {rd }}$ & 52 & 152.25 & 7.35 & \\
\hline \multirow{2}{*}{ Wt $(\mathrm{kg})$} & $2^{\text {nd }}$ & 50 & 47.10 & 5.49 & \multirow{2}{*}{$0.0001^{*}$} \\
\hline & $3^{\text {rd }}$ & 52 & 84.60 & 8.32 & \\
\hline \multirow{2}{*}{ Pulse Rate (bpm) } & $2^{\text {nd }}$ & 50 & 87.76 & 10.72 & \multirow{2}{*}{0.121} \\
\hline & $3^{\text {rd }}$ & 52 & 91.07 & 10.67 & \\
\hline \multirow{2}{*}{ SBP (mmHg) } & $2^{\text {nd }}$ & 50 & 105.18 & 8.64 & \multirow{2}{*}{0.579} \\
\hline & $3^{\text {rd }}$ & 52 & 103.94 & 13.27 & \\
\hline \multirow{2}{*}{ DBP (mmHg) } & $2^{\text {nd }}$ & 50 & 65.28 & 7.69 & \multirow{2}{*}{$0.0001^{* *}$} \\
\hline & $3^{\text {rd }}$ & 52 & 91.09 & 13.89 & \\
\hline \multirow{2}{*}{ CPT (mmHg) } & $2^{\text {nd }}$ & 50 & 8.30 & 9.70 & \multirow{2}{*}{$0.015^{*}$} \\
\hline & $3^{\text {rd }}$ & 52 & 4.47 & 5.41 & \\
\hline
\end{tabular}

A Highly Significant Difference was observed in Wt, DBP, DBP response to CPT of case group of $2^{\text {nd }}$ trimester when compared with $3^{\text {rd }}$ trimester; No significant difference was observed in Age, Hb, Ht, pulse rate, SBP (Table No. 2).

Table No. 3:Comparison of Mean of Parameters Between Case \& Control Group (2 ${ }^{\text {nd }}$ Trimester)

\begin{tabular}{|l|c|c|c|c|c|}
\hline & Group & N & Mean & SD & p-value \\
\hline \multirow{2}{*}{ Age (Years) } & Case & 50 & 21.94 & 2.90 & \multirow{2}{*}{0.541} \\
\cline { 2 - 5 } & Control & 30 & 22.40 & 3.74 & \\
\hline \multirow{2}{*}{$\mathrm{Hb}(\mathrm{gm} \%)$} & Case & 50 & 9.06 & 0.79 & \multirow{2}{*}{$0.000^{* *}$} \\
\cline { 2 - 5 } & Control & 30 & 11.36 & 0.50 & \\
\hline
\end{tabular}




\begin{tabular}{|c|c|c|c|c|c|}
\hline & Group & $\mathbf{N}$ & Mean & SD & p-value \\
\hline \multirow{2}{*}{$\mathrm{Ht}(\mathrm{cm})$} & Case & 50 & 150.18 & 5.06 & \multirow{2}{*}{0.545} \\
\hline & Control & 30 & 150.90 & 5.23 & \\
\hline \multirow{2}{*}{ Wt (kg) } & Case & 50 & 47.10 & 5.49 & \multirow{2}{*}{0.480} \\
\hline & Control & 30 & 48.56 & 12.82 & \\
\hline \multirow{2}{*}{ Pulse Rate (bpm) } & Case & 50 & 87.76 & 10.72 & \multirow{2}{*}{0.291} \\
\hline & Control & 30 & 90.40 & 10.80 & \\
\hline \multirow{2}{*}{$\mathrm{SBP}(\mathrm{mmHg})$} & Case & 50 & 105.18 & 8.64 & \multirow{2}{*}{0.681} \\
\hline & Control & 30 & 104.33 & 9.26 & \\
\hline \multirow{2}{*}{ DBP (mmHg) } & Case & 50 & 65.28 & 7.69 & \multirow{2}{*}{0.812} \\
\hline & Control & 30 & 64.86 & 7.15 & \\
\hline \multirow{2}{*}{ CPT (mmHg) } & Case & 50 & 8.30 & 9.70 & \multirow{2}{*}{1.000} \\
\hline & Control & 30 & 8.30 & 11.89 & \\
\hline
\end{tabular}

Except $\mathrm{Hb}$ value, No Significant Difference in Age, Wt, Ht, Supine Pulse Rate, SBP, DBP, DBP response to CPT as observed in Case Group of $2^{\text {nd }}$ trimester when compared with Control Group of $2^{\text {nd }}$ trimester (Table No. 3 ).

Table No. 4: Comparison of Mean of Parameters between Case \& Control Group ( $3^{\text {rd }}$ Trimester)

\begin{tabular}{|c|c|c|c|c|c|}
\hline & Group & $\mathbf{N}$ & Mean & SD & p-value \\
\hline \multirow{2}{*}{ Age (Years) } & Case & 52 & 21.82 & 2.88 & \multirow{2}{*}{0.427} \\
\hline & Control & 46 & 22.32 & 3.30 & \\
\hline \multirow{2}{*}{$\mathrm{Hb}(\mathrm{gm} \%)$} & Case & 52 & 9.07 & 0.80 & \multirow{2}{*}{$0.000^{* *}$} \\
\hline & Control & 46 & 11.63 & 0.73 & \\
\hline \multirow{2}{*}{$\mathrm{Ht}(\mathrm{cm})$} & Case & 52 & 152.25 & 7.35 & \multirow{2}{*}{0.870} \\
\hline & Control & 46 & 152.02 & 6.22 & \\
\hline \multirow{2}{*}{ Wt (kg) } & Case & 52 & 84.60 & 8.32 & \multirow{2}{*}{0.090} \\
\hline & Control & 46 & 81.85 & 7.48 & \\
\hline \multirow{2}{*}{ Pulse Rate (bpm) } & Case & 52 & 91.07 & 10.67 & \multirow{2}{*}{0.535} \\
\hline & Control & 46 & 92.65 & 14.27 & \\
\hline \multirow{2}{*}{$\mathrm{SBP}(\mathrm{mmHg})$} & Case & 52 & 103.94 & 13.27 & \multirow{2}{*}{$0.006^{* *}$} \\
\hline & Control & 46 & 96.10 & 14.15 & \\
\hline \multirow{2}{*}{ DBP (mmHg) } & Case & 52 & 91.09 & 13.89 & \multirow{2}{*}{$0.000^{* *}$} \\
\hline & Control & 46 & 109.58 & 12.85 & \\
\hline \multirow{2}{*}{ CPT (mmHg) } & Case & 52 & 4.47 & 5.41 & \multirow{2}{*}{0.051} \\
\hline & Control & 46 & 5.27 & 6.46 & \\
\hline
\end{tabular}

A Highly Significant Difference was observed in Hb, SBP, DBP of Case Group of $3^{\text {rd }}$ trimester when compared with Control Group during $3^{\text {rd }}$ trimester; But No Significant Difference was observed in Age, Ht, Wt, Pulse rate, DBP response to CPT (Table No. 4). 
Table No. 5:Association of Value of DBP During CPT in Moderately Anaemic Pregnancy \& in Healthy Pregnancy

\begin{tabular}{|c|c|c|c|c|c|c|c|}
\hline \multirow{2}{*}{ AFT } & \multirow{2}{*}{ Value } & \multicolumn{3}{|c|}{$2^{\text {nd }}$ Trimester } & \multicolumn{3}{|c|}{$3^{\text {rd }}$ Trimester } \\
\hline & & Control $(n=30)$ & Case $(n=50)$ & p-value & Control $(n=46)$ & Case $(n=52)$ & p-value \\
\hline \multirow{2}{*}{$\begin{array}{l}\text { CPT } \\
(\mathrm{mmHg})\end{array}$} & $\geq 10^{\dagger}$ & 13 & 20 & \multirow{2}{*}{0.769} & 21 & 21 & \multirow{2}{*}{0.598} \\
\hline & $<10^{\dagger \dagger}$ & 17 & 30 & & 25 & 31 & \\
\hline
\end{tabular}

$\dagger$ is considered as Normal response to Test., $\dagger \dagger$ is considered as Abnormal response to Test.

The Chi-square Test value shows that the observed DBP response to CPT in moderately anaemic pregnancy during $2^{\text {nd }} \& 3^{\text {rd }}$ trimester is not due to Chance (Table No. 5).

\section{Discussion}

CDKUOetal (2000) has described Biphasic Changes in Autonomic cardiovascular Control during Pregnancy which include higher Vagal \& lower Sympathetic Modulation in the $1^{\text {st }}$ trimester in Supineposition, because of increased Blood Volume, which is lasting upto mid-pregnancy. As gestational age increases further, Aortocaval compression caused by the Enlarging Gravid Uterus further compromises VenousReturn \& CO,leading to a shift in Autonomic Nervous Activity towards an evenHigher Sympathetic \& Lower Vagal Modulation in the $3^{\text {rd }}$ trimester of Pregnancy. ${ }^{12}$ which is observed during our study irrespective of level of Hbin Blood. There are reports of an increase in Resting Peripheral sympathetic Activity during $3^{\text {rd }}$ trimester as measured by Peroneal Nerve Microneurography in patients withPIH as compared to Healthy Pregnant \& Non-pregnant Females, Which returned to normal level in post-partum period. ${ }^{13}$ It is generally accepted that the pre-eclampsia is characterised by the low Circulationg Volume \& high Vascular Resistance ${ }^{14,15}$ \& also a higher $\mathrm{CO}$ was observed in early Pregnancy, who developed pre-Eclampsia later in pregnancy compared to healthy Pregnant Women. ${ }^{16,17}$ this supports the high SBP value observed in our study group $2^{\text {nd }}$ trimester of pregnancy with Moderateanaemia. There is increased refractoriness to Circulating Angiotensin II during normal Pregnancy, But women who destined to develop PIH or Pre-eclampsia have increased sensitivity to Angiotensin II, as a result of an Alteration in vessel wall Refractoriness rather than the Consequence of Changes in blood Volumeor Circulating renin-angiotensin Levels. Majortiy of study authors observed no Difference in Heart Rate between healthy Pregnant Woman \& Pre- eclamptic Woman. ${ }^{4}$ this explains unreliability of Heart Rate as a sole parameter to rule out High risk Case. Studies have shown that Neurovascular Transduction is generally Reduced in Normotensive Pregnancy, thereby dissociating Sympathetic Nerve activity from Vascular Resistance \& arterial Pressure during CPT. ${ }^{18}$ This explains the Variability in Observations of our Study. BP is maintained by CO \& TPR; these two show Significant inverse Relationship that is, Higher the $\mathrm{CO}$ the lower is the Vascular Resistance. Sympathetic Nerves play a major role in regulating BP by Controlling the Resistance of the arterioles \& the capacity of the Veins. During Cardiac function at Rest, they play only a minor Role in controlling the Strength \& the Rate of the Heart Beat. During Physiological Stress however, increased Sympathetic Activity combined with Decreased Parasympathetic Activity increases the Rate \& force of Contraction of the heart leading to an increase in CO. ${ }^{19}$ MELANIE J BLAKE, Allison Martin et al (2000) has found that there occurs Significant change in supine SBP \& DBP during different trimester in Normotensive Pregnancies ${ }^{20}$, which is consistent with finding of our study. Total Peripheral Resistance (TPR) falls Significantly by at least 6 weeks of gestational age $\&$ reaches a Nadir of $40 \%$ below Non-pregnant Values by mid-gestation. Fall in TPR also makes $\mathrm{CO}$ to fall. The $\mathrm{CO}$ depends on patient position $\&$ is greatest when measured in Lateral Recumbent position. This is most notable during last Trimester. When, with the woman in supine Position, the gravid uterus \& foetus impede venous Return (VR)to the heart. There is decrease inCO by $0.6 \mathrm{~L} / \mathrm{min}$ in supine position. There is selective regional distribution of this Physiologic increase inCO. Uterine blood flow increases 10 fold to between 500 to $800 \mathrm{ml} / \mathrm{min}$. Renal Blood Flow increases significantly by $50 \%$ during Pregnancy. ${ }^{21,22}$ BP decreases in Pregnancy beginning as early as $7^{\text {th }}$ week. This early drop probably represents incomplete Compensation of the fall inTPR by the increase in CO. When measured 
in Sittingor Standing positions, SBP remains relatively stable throughout Pregnancy, whereas DBP decreases by a maximum of $10 \mathrm{~mm} \mathrm{Hg}$ at 28 wks of gestation \& then increases towards non-pregnant levels by term. In left Lateral position both decreases below Non-pregnant values at 24-32 wks of gestation ${ }^{23,24}$; which is not included in our study. The rise in Systemic Resistance \& fall in $\mathrm{CO}$ without change in Arterial Pressure observed after assumption of the Upright posture in adult imply Peripheral Vasoconstriction \& indicate that the circulatory changes of chronic Anaemia are labile rather than fixed. ${ }^{25}$ explains the need to select stress test like CPT for our study group. The reduced BP response reported could be due to antagonistic effect of the products of the utero Placental unit, such as progesterone or a diminished Contractile Response of the blood vessels to Adrenaline ${ }^{26}$ probably explains the low DBP response than the cutoff value while performing CPTin both the groups. No Significant difference in pulse rate observed in our study. Data suggested that Tachycardia \& Increased flow Velocity are not physiologically adapted to prolonged strain but rather are mechanisms to meet acute bodily stresses such as fever,exercise, hyper metabolism \& acute anaemia. ${ }^{25}$ William B Porter et $\mathrm{al}^{25}$ has described four mechanisms operating in anaemic patients which may increase the supply of oxygen to tissues when the oxygen carrying capacity of the blood is reduced; under conditions of rest, a rapid velocity flow $\&$ tachycardia with an increase in minute volume of $\mathrm{CO}$ is the first response to anaemia. As compensation develops, tachycardia \& increased velocity flow are largely replaced by selective Shunting of blood \& the removal of an increasing percentage of Oxygen in the tissue capillaries from each gram of circulating $\mathrm{Hb}$. A reduction in TPR reduces cardiac work, thus tend to balance the effect of the elevation in $\mathrm{CO}$. In patients with highest $\mathrm{CO}$, tachycardia was not a prominent feature. Even breathing 100\% oxygen show no change in elevated $\mathrm{CO}$ in anaemia. ${ }^{25,27}$ this supports our study result; the high SBP \& low DBP observed during $3^{\text {rd }}$ trimester of pregnancy with moderate anaemia. Martin et $\mathrm{al}^{25}$ revealed that the severity ofChronic anaemia didnot correlate well with the level ofCO.They also revealed that the mean Venous Pressure was within normal limits for the anaemic Group \& generally was unchanged after the therapy of Anaemia. The decreased Arterial Pressurein Anaemia might be a reflection of a number of events including generalised Vasodilatation \& a reduced Bloodvolume. Maintenance of a normal Venous Pressure may well represent an effort to overcome these latter changes by Vasoconstriction \& increasing the return of blood to the heart. The acute, immediate reversal of the high Output state of Anaemia by orthostatic Stress or by vasoconstrictor Drug indicates that the increased Blood flow is primarily mediated by lowered Peripheral Resistance due to vasodilatation rather than to low Blood Viscosity. ${ }^{28,29}$ It has been postulated that the Hyperkinetic Response to anaemia in patients at rest occurs only when the Concentration of $\mathrm{Hb}$ falls beneath $7 \mathrm{gm} / \mathrm{dl}^{30}$ explains the role of CPT to find out underlying Subclinical pathogenesis. Martin Duke et.al. ${ }^{25}$ had revealed that in many patients, the hemodynamic values that appeared within normal limits in the Anaemic state were actually Altered when compared to that particular individuals normal state after therapy;explains the objective of performing this study.

\section{Conclusion}

This study has found CPT as simple, safe, cost effective, reliable test aiding to understand Pathophysiology of Anaemiaduring Late Gestation. It is also useful tool to Predict \& Screen high risk Pregnancy among Anaemics for early Intervention. Many such studies \& further evaluation are needed to support our observation forms the limitation of our study.

Ethical Clearance: Taken from ethical committee of smimer medical college and hospital.

\section{Source of Funding: Self}

\section{Conflict of Interest: Nil}

\section{References}

1. Al Hinai F: Complication of pregnancy \& delivery among omani women in different parity groups, MSc. Thesis at sultan Qakoos University, college of medicine, 2003.

2. Emre karasahin, Seyit Temel Gyhan: Maternal anaemia \& perinatal outcome: perinatal journal : vol : 15,2007.

3. Demayer EM, Tegman A;Prevalence of anaemia in the world health organ Qlty 1998; 38; 302-16.

4. Rang S, WolfH, Von Montrans G: Non invasive assessment of autonomic cardiovascular control in normal human pregnancy \& pregnancy associated hypertensive disorders: A review, J Hypertension: 2002; 20: 2111- 2119.

5. Dekker GA, SibaiBM:Etiology \& pathogenesis of pre-eclampsia:current concept; Am J obstetgynecol 


$$
\text { 1998.179;1359. }
$$

6. Lindheimer MD, Wordruff TK: Activin A, Inhibin A \& pre eclampsia. Lancet 1997; 349(9061):12661267.

7. Stamilio DM, SEhdert HM, Morgan MA, Propert K, Macones GA: Can antenatal clinical \& biochemical markers predict the development of severe preeclampsia?; Am J Obstet Gynecol 2000;182(3):589.

8. Autonomic function Lab, AIIMS new delhi: Cardiovascular Autonomic Function Testing; Principles \& Method.

9. Nadinikapoor, Rajeev Sharma, Munish Ashat, Anju Huria, ghanshyam Mishra: Assessment of cardiovascular autonomic functions to predict development of pregnancy induced hypertension. NJOG 2011 May-June;6(1):41-45.

10. Woisetschlager $\mathrm{C}$, waldenhofer $\mathrm{U}$, Bur A et al: Increased blood pressure response to $\mathrm{CPT}$ in pregnant women developing pre eclampsia: Journal of Hypertension 2000, 18(4):399-403

11. NEILSEN, H.E: The circulation in anaemic condition, Acta.Med.sc \& inav.81;571,1934.

12. C.D.Kuo, G Y chen, M.J.Yang, H.M.LO \& Y.S. Tsai: Biphasic changes in autonomic nervous activity during pregnancy. British J of Anaesthesia 2000;84(0):323-9.

13. John $\mathrm{p}$ Greenwood,Eleanor M Scott, John B Stoker, James J Walker \& David A S, G Mary: Sympathetic neural mechanism in normal \& hypertensive pregnancy in human; Circulation 2001;104:22002204.

14. Visser W, Wallen burg HC: Central hemodynamic observations in untreated pre eclamptic patients. Hypertension 1991:17;1072-1077.

15. Robert JM, Redman CW: Pre-eclampsia more than pregnancy induced hypertension. Lancet 1993:341; 1447-1451.

16. Bosio PM, Mckenna PJ, Conroy R, O’Herlihy . C: Maternal central hemodynamics in hypertensive disorders of pregnancy. Obstetgynecol 1999; 94;978-984.

17. Easterling TR, Benedetti JJ, Scumaker BL, Millard SP: Maternal hemodynamics in normal \& pre eclamptic pregnancies: A longitudinal study. Obstet Gynecol 1990; 76; 1061-1069.
18. Charlotte W. Usselman, Paige K. Wakefield: Regulation of Sympathetic Nerve Activity During the CPT in Normotensive Pregnant \& Nonpregnant Women (Hypertension. 2015;66:00-00.

19. Samson Wright's, Applied Physiology, $13^{\text {th }}$ edition, oxford medical publication; 1999.

20. Melanie J Blake, Allison, MARTIN: Changes in baroreceptor sensitivity for heart rate during normotensive pregnancy \& the puerperium; Clinical science (2000)98,259-268.

21. Michael de sweit: Medical disorders in obstetric practice; $3^{\text {rd }}$ edi. Oxford Blackwell Scientific: 1995.

22. Duvekott JJ, Cheriex EC, Tan WD, Heidendal GA, Peters LL: Early pregnancy changes in hemodyanmics \& volume homeostasis are consecutive adjustments triggered by primary fall in systemic vascular tone: Basic Res Cardiol 1994:89:270 - 277.

23. Duvekot JJ, Cheriex EC, Tan WD, Heidendal GA, Perters LL: Early pregnancy changes in hemodynamics \& volume homeostasis are consecutive adjustments triggered by primary fall in systemic vascular tone:Am J obstetgynecol 1993:169;1382.

24. Duvekot JJ, Peters L.L.H: Maternal cardiovascular hemodynamic adaptation to pregnancy: obstetgynecol 1994: 49; 51-53.

25. Martin duke \& Walter H A elmann (1969): The hemodynamic response to chronic anaemia: Circulation: 39: 503 -515.

26. Whittaker PG, Gerrard J, Linde T: Catecholamine response to changes in posture during normal pregnancy. Br J obstetGynecol 1985; 92: 582- 92.

27. STORSTEIN: On the effect of pure oxygen breathing on the circulation in anoxemia. Acta Med Sc \& 143(suppl. 269):1952.

28. Richardson T Q, \& Guyton A C: Effects of polycythemia \& anaemia onCO \& other circulatory factors. Amer J Physiol 197:1167, 1959.

29. Richardson $\mathrm{T}$ Q, \& Guyton A C: Effect of hematocrit on venous return. circulation Research 9:157,1961.

30. Brannon, E.S., Merrill, A.J., Warren J.V. \& Stead E.A. Jr: The CO in patients with chronic anaemias measured by the technique of right atrial catheterization. J. Clin. Investigation 24;332,1945. 